\title{
Hubungan Stimulasi Ibu dengan Perkembangan Anak Usia 0-3 Tahun di Kelurahan Penengahan Raya Kecamatan Kedaton Bandar Lampung
}

\author{
Roro Rukmi Windi Perdani, ${ }^{1}$ Dara Marissa Widya Purnama, ${ }^{2}$ Nisrina Afifah, ${ }^{2}$ Anugerah Indah Sari, ${ }^{2}$ Sabrina Fahrieza ${ }^{2}$ \\ ${ }^{1}$ Bagian Ilmu Kesehatan Anak, ${ }^{2}$ Fakultas Kedokteran Universitas Lampung/RSUD Dr. H. Abdoel Moeloek, Lampung
}

Latar belakang. Usia 0-3 tahun merupakan golden age period yang tepat untuk perkembangan anak. Perkembangan anak meliputi kemampuan gerak motorik kasar, motorik halus, bahasa, dan personal sosial. Salah satu faktor yang sangat mempengaruhi perkembangan anak adalah pemberian stimulasi.

Tujuan. Mengetahui hubungan stimulasi ibu dengan perkembangan anak usia 0-3 tahun di Kelurahan Penengahan Raya Kecamatan Kedaton Bandar Lampung.

Metode. Desain penelitian ini kuantitatif observasional dengan pendekatan cross sectional dan teknik consecutive sampling. Data merupakan data primer dengan instrumen kuesioner yang sudah diuji validitas dan reliabilitasnya untuk menilai stimulasi ibu dan hasil skrining perkembangan dengan Denver II. Analisis data menggunakan uji chi-square.

Hasil. Pada 80 responden, 44 (55\%) ibu memberikan stimulasi motorik kasar baik dan 36(45\%) kurang, 39(48,8\%) ibu memberikan stimulasi motorik halus baik dan $41(51,2 \%)$ kurang. 46 (57,5\%) ibu memberikan stimulasi bahasa baik dan 34(42,5\%) kurang. $33(41,2 \%)$ ibu memberikan stimulasi personal sosial baik dan 47(58,8\%) kurang. Anak dengan perkembangan motorik kasar, motorik halus, bahasa dan personal sosial dalam kategori normal berturut-turut adalah 61 (76,2\%), 61 (76,2\%), 45 (56,2\%) dan 68 (85\%). Terdapat hubungan yang bermakna antara stimulasi ibu dengan perkembangan motorik kasar $(\mathrm{p}=0,004)$, motorik halus $(\mathrm{p}=0,025)$, bahasa $(\mathrm{p}=0,000)$ dan personal sosial $(\mathrm{p}=0,001)$.

Kesimpulan. Terdapat hubungan stimulasi ibu dengan perkembangan anak usia 0-3 tahun di Kelurahan Penengahan Raya Kecamatan Kedaton Bandar Lampung. Sari Pediatri 2021;22(5):304-10

Kata kunci: 0-3 tahun, anak, perkembangan, stimulasi

\section{The Relationship between Mother's Stimulation and Development of 0 - 3 Year Old Children in Penengahan Raya Subdistrict Kedaton Distric Bandar Lampung}

Roro Rukmi Windi Perdani, ${ }^{1}$ Dara Marissa Widya Purnama, ${ }^{2}$ Nisrina Afifah, ${ }^{2}$ Anugerah Indah Sari, ${ }^{2}$ Sabrina Fahrieza ${ }^{2}$

Background. Age 0-3 years is a golden age period and is appropriate for children's development. Children's development includes the ability of gross motor movements, fine motor skills, language, and social person. One of the factors that greatly influence a child's development is stimulation.

Objective. The study aimed to determine the relationship between mother stimulation and the development of $0-3$ year old children in Penengah Raya Subdistrict, Kedaton District, Bandar Lampung.

Method. It is a quantitative observational research with cross sectional approach and consecutive sampling technique. Data was taken by using validated questionnaires to assess maternal stimulation and the Denver II test to screen children's development. Then it was analyzed by using the chi-square test.

Results. There were 80 respondents, 44 (55\%) mothers gave good gross motor stimulation and 36 (45\%) less one. 39 (48.8\%) mothers gave good fine motor stimulation, and 41 (51,2\%) less stimulation. $46(57.5 \%)$ mothers gave good language stimulation, and $34(42,5 \%)$ less one. $33(41.2 \%)$ mothers gave good personal social stimulation and $47(58.8 \%)$ mothers less stimulation. Children who had gross motor development, fine motor skills, language and social personalities in the normal categories were 61 (76.2\%), 61 $(76.2 \%), 45(56.2 \%)$ and $68(85 \%)$ respectively. There was a significant relationship between maternal stimulation with gross motor development $(\mathrm{p}=0.004)$, fine motor $(\mathrm{p}=0.025)$, language $(\mathrm{p}=0,000)$, and personal social $(\mathrm{p}=0.001)$.

Conclusion. There is a relationship between maternal stimulation with the development of $0-3$ year old children in Penengah Raya Village, Kedaton District, Bandar Lampung. Sari Pediatri 2021;22(5):304-10

Keywords: 0-3 years old, children, development, stimulations

Alamat korespondensi: Roro Rukmi Windi Perdani. Bagian Ilmu Kesehatan Anak, ${ }^{2}$ Fakultas Kedokteran Universitas Lampung/RSUD Dr. H. Abdoel Moeloek, Lampung. Email: rororwp@gmail.com 
U sia 0-3 tahun merupakan periode emas (golden age period) dan tepat untuk perkembangan anak yang meliputi aspek fisik, kognitif, emosi, dan sosial. ${ }^{1}$ Anak mempunyai keinginan belajar yang luar biasa karena sedang terjadi periode pacu tumbuh otak (brain growth spurt) pada masa ini, ketika otak mengalami perkembangan yang sangat cepat.

Kemampuan motorik merupakan salah satu kemampuan anak yang berkembang saat usia dini. Dua jenis perkembangan motorik, yaitu motorik kasar dan halus. Motorik kasar adalah gerakan yang memerlukan koordinasi kelompok otot-otot anak yang dapat membuat mereka melompat, memanjat, berlari, dan menaiki sepeda. Motorik halus adalah gerakan yang memerlukan koordinasi tangan dan mata yang dipengaruhi oleh kesempatan untuk belajar dan berlatih, seperti menggambar, menulis, menggunting dan memindahkan benda. ${ }^{2}$ Perkembangan bahasa dimulai secara bertahap yang terjadi selama tiga tahun pertama kehidupan. ${ }^{3}$ Personal sosial adalah hal-hal yang berhubungan dengan kemampuan mandiri, seperti memakai baju sendiri, pergi ke toilet sendiri, bersosialisasi atau berkomunikasi dengan orang lain dan berinteraksi dengan lingkungan sekitar. ${ }^{4}$

Stimulasi adalah kegiatan yang merangsang kemampuan anak dan memengaruhi pertumbuhan dan perkembangan serta menjadi penguat dalam proses perkembangan anak. Stimulasi juga merupakan kebutuhan dasar anak, yaitu asah yang akan menunjang perkembangan anak menjadi lebih optimal. ${ }^{4}$ Anak usia 0-3 tahun merupakan waktu yang sangat penting dalam perkembangan otak, meliputi perkembangan fisik, sosio-emosional dan Bahasa atau kognitif. Pertumbuhan otak tergantung dari banyaknya faktor interaksi dan saling ketergantungan seperti genetik, status kesehatan dan nutrisi, kualitas interaksi antara ibu dan anak serta karakteristik lingkungan. ${ }^{5}$ Salah satu faktor yang sangat memengaruhi perkembangan balita ialah dengan diberikan stimulasi yang baik. Perkembangan otak dalam menyusun struktur syaraf sangat dipengaruhi oleh interaksi antara lingkungan dan rangsangan. ${ }^{6}$ Penelitian Marischa menjelaskan bahwa pengetahuan orang tua mengenai stimulasi motorik kasar berhubungan dengan perkembangan motorik anaknya. ${ }^{7}$ Sementara Hartanto pada tahun 2011 menjelaskan bahwa terdapat pengaruh stimulasi terhadap perkembangan bicara anak 1-3 tahun. ${ }^{8}$
Bandar Lampung memiliki 30 Puskesmas yang tersebar di berbagai kecamatan. Salah satu puskesmas yang ada di Bandar Lampung adalah Puskesmas Kedaton. Kecamatan Kedaton berada di lokasi yang cukup strategis di Bandar Lampung dan tercatat 11 anak mengalami keterlambatan perkembangan. Terdapat 31 posyandu yang berada dalam wilayah kerja Puskesmas Kedaton yang tersebar di 7 kelurahan. Salah satu kelurahan yang aktif dalam kegiatan posyandu dan baru terbentuk adalah Kelurahan Penengahan Raya. ${ }^{9}$ Pada kelurahan tersebut belum pernah dilakukan penelitian perkembangan anak, sehingga peneliti tertarik untuk melihat hubungan stimulasi terhadap perkembangan anak usia 0-3 tahun di kelurahan tersebut.

\section{Metode}

Penelitian ini merupakan penelitian cross sectional dari bulan Oktober 2017 - bulan Desember 2017 di wilayah kerja Kelurahan Penengahan Raya Kecamatan Kedaton, Bandar Lampung. Populasi penelitian adalah ibu dan anak usia 0-3 tahun yang mengunjungi posyandu di Kelurahan Penengahan Raya Kecamatan Kedaton Bandar Lampung. Kriteria inklusi adalah ibu yang bersedia balitanya dilakukan tes Denver II, anak kooperatif untuk dilakukan tes, dan status gizi anak antara $-2<\mathrm{SD}<2$ berdasarkan BB/PB. Anak usia 0-3 tahun yang memiliki riwayat penyakit (hidrosefalus, sindrom down, retardasi mental, autisme, Attention deficit hyperactive disorder, cerebral palsy), gizi buruk dan balita yang berkunjung sedang sakit, merupakan kriteria eksklusi dalam penelitian ini. Pemilihan sampel dilakukan dengan metode consecutive sampling. Pemeriksaan Denver II dilakukan oleh seorang dokter spesialis anak dengan menggunakan alat peraga Denver II yang terstandar.

Alat pengumpulan data yang digunakan adalah kuesioner yang sudah divalidasi mengenai stimulasi perkembangan yang akan diberikan kepada orangtua, lembar tes Denver II untuk skrining perkembangan anak, mikrotoise, alat ukur panjang badan bayi, dan timbangan berat badan anak dan bayi serta mainan. Data yang didapat merupakan data primer yang berasal dari pengisian kuesioner dan pemeriksaan Denver II. Variabel bebas dalam adalah stimulasi ibu yang dibedakan menjadi stimulasi perkembangan motorik 
halus, bahasa, dan motorik kasar yang masing-masing dikategorikan menjadi baik dan kurang.

Uji validitas dan reliabilitas telah dilakukan terhadap 24 anak usia 0-3 tahun beserta orang tuanya di Posyandu di Kecamatan Kedaton yang tidak termasuk dalam penelitian sesungguhnya. Pengujian apakah kuesioner tersebut memenuhi syarat validitas, maka digunakan korelasi Pearson. Analisis dengan cara menghitung koefisien korelasi antara masing-masing nilai pada nomor pertanyaan dengan nilai total dari nomor pertanyaan tersebut. Selanjutnya, signifikansi koefisien korelasi yang diperoleh (r) diuji dengan cara membandingkannya dengan $r$ tabel. Bila $t$ hitung > dari $t$ tabel atau $r$ hitung $>$ dari $r$ tabel, maka nomor pertanyaan tersebut valid. ${ }^{8}$ Pada penelitian ini $r$ tabel yang digunakan adalah 0,3882 dan didapatkan hasil uji validitas pada kuesioner valid karena $r$ hitung lebih besar daripada $\mathrm{r}$ tabel. Reliabilitas kuesioner diuji dengan Cronbach's Alpha dan instrumen dikatakan mempunyai reliabilitas tinggi jika didapatkan nilai Cronbach's Alpha 0,70-0,90. Nilai Cronbach's Alpha kuesioner penelitian ini termasuk dalam rentang tersebut sehingga dikatakan valid.

Variabel terikat adalah perkembangan anak yang terdiri dari motorik kasar, motorik halus, bahasa, dan personal sosial yang masing-masing dikategorikan menjadi normal dan suspek. Stimulasi baik jika nilai total lebih dari atau sama dengan median dan kurang jika nilai total kurang dari median. Adapun cara pemeriksaan dan interpretasi Denver II sesuai dengan standar baku pemeriksaan dan interpretasi Denver II. Data kemudian dianalisis dengan menggunakan uji statistik. Uji statistik yang digunkaan dalam penelitian ini adalah uji chi square dengan tingkat kepercayaan $95 \%$ dan $=0,05 \%$. Nilai $\mathrm{p}$ (p-value $) \leq 0,05(0,004)$, maka hasil perhitungan statistik bermakna (signifikan) atau menunjukkan adanya hubungan antara variabel bebas dan terikat.

Penelitian ini telah disetujui oleh komisi etik Fakultas Kedokteran Universitas Lampung no. 228/ UN26.8/DL/2018. Persetujuan diminta dalam bentuk inform concent. Identitas pasien dirahasiakan.

\section{Hasil}

Selama 2 bulan penelitian didapatkan 80 subyek penelitian yang memenuhi kriteria inklusi dan eksklusi.
Tabel 1. Karakteristik ibu $(\mathrm{n}=80)$

\begin{tabular}{lcc}
\hline Karakteristik & Jumlah (n) & $\%$ \\
\hline Pendidikan ibu & & \\
SD & 4 & 5 \\
SMP & 20 & 25 \\
SMA & 46 & 57,5 \\
Perguruan tinggi & 10 & 12,5 \\
Usia ibu (tahun) & & \\
$\quad 25$ & 18 & 22,5 \\
$26-35$ & 54 & 67,5 \\
$>35$ & 8 & 10 \\
Pekerjaan ibu & & \\
Wirausaha & 7 & 8,8 \\
Karyawati & 5 & 6,3 \\
Ibu rumah tangga & 68 & 85 \\
\hline
\end{tabular}

Tabel 2. Distribusi stimulasi $(\mathrm{n}=80)$

\begin{tabular}{lcc}
\hline Stimulasi & Jumlah (n) & $\%$ \\
\hline Motorik kasar & & \\
$\quad$ Baik & 44 & 55 \\
$\quad$ Kurang & 36 & 45 \\
Motorik halus & & \\
$\quad$ Baik & 39 & 48,8 \\
$\quad$ Kurang & 41 & 51,2 \\
Bahasa & & \\
$\quad$ Baik & 46 & 57,5 \\
$\quad$ Kurang & 34 & 42,5 \\
Personal sosial & & \\
$\quad$ Baik & 33 & 41,2 \\
$\quad$ Kurang & 47 & 58,8 \\
\hline
\end{tabular}

Tabel 3. Perkembangan

\begin{tabular}{lcc}
\hline Perkembangan & Frekuensi (F) & $\%$ \\
\hline Motorik kasar & & \\
$\quad$ Normal & 61 & 76,2 \\
Suspek & 19 & 23,8 \\
Motorik halus & & \\
$\quad$ Normal & 61 & 76,2 \\
$\quad$ Suspek & 19 & 23,8 \\
Personal sosial & & \\
$\quad$ Normal & 68 & 85 \\
$\quad$ Suspek & 12 & 15 \\
Bahasa & & \\
$\quad$ Normal & 45 & 56,2 \\
Suspek & 35 & 43,8 \\
\hline
\end{tabular}


Roro Rukmi Windi Perdani dkk: Hubungan stimulasi ibu dengan perkembangan anak usia 0-3 tahun

\begin{tabular}{lcccc}
\multicolumn{5}{l}{ Tabel 4. Hubungan stimulasi ibu dengan perkembangan } \\
\hline $\begin{array}{l}\text { Stimulasi } \\
\text { Perkembangan }\end{array}$ & Normal (n) & Suspek (n) & Nilai p & $95 \%$ CI \\
\hline $\begin{array}{l}\text { Motorik kasar } \\
\quad \text { Baik }\end{array}$ & 39 & 5 & $0,004^{*}$ & $2,153-2,485$ \\
$\quad$ Kurang & 22 & 14 & & \\
Motorik halus & & & & \\
$\quad$ Baik & 34 & 5 & $0,025^{*}$ & $1,128-11,017$ \\
$\quad$ Kurang & 27 & 14 & & \\
$\begin{array}{l}\text { Personal sosial } \\
\quad \text { Baik }\end{array}$ & 33 & 0 & $0,001^{*}$ & $0,409-0,648$ \\
$\quad$ Kurang & 35 & 12 & & \\
Bahasa & & & & \\
$\quad$ Baik & 43 & 3 & $0,000^{*}$ & $36,176-1453,830$ \\
$\quad$ Kurang & 2 & 32 & & \\
${ }^{*}$ Chi-square ${ }^{*}$ Fisher exact & & & &
\end{tabular}

Data karakteristik tertera pada Tabel 1. Dari 80 subyek penelitian didapatkan 4 ibu subyek berpendidikan SD (5\%), 20 berpendidikan SMP (25\%), 46 berpendidikan SMA (57,5\%) dan 10 berpendidikan perguruan tinggi $(12,5 \%)$. Delapan belas ibu subyek berusia $\leq 25(22,5 \%)$ tahun, 54 berusia 26-35 (67,5\%), dan 8 berusia $>35$ (10\%). Pekerjaan ibu terdiri dari 7 $(8,8 \%)$ wirausaha, $5(6,3 \%)$ karyawati, dan 68 (85\%) ibu rumah tangga. Dari 80 responden, 44 (55\%) ibu memberikan stimulasi motorik kasar yang baik dan 36 (45\%) ibu memberikan stimulasi kurang, 39 (48,8\%) ibu memberikan stimulasi motorik halus yang baik dan $41(51,2 \%)$ ibu memberikan stimulasi kurang. Stimulasi bahasa yang termasuk kategori baik diberikan oleh $46(57,5 \%)$ ibu dan yang termasuk kategori kurang sejumlah 34 (42,5\%). Stimulasi personal sosial yang baik diberikan oleh $33(41,2 \%)$ ibu dan stimulasi yang kurang oleh $47(58,8 \%)$ ibu. Sementara itu anak yang memiliki perkembangan motorik kasar, motorik halus, personal sosial dan bahasa dalam kategori normal berturut-turut adalah 61 (76,2\%), 61 (76,2\%), 68 $(85 \%)$, dan 45 (56,2\%). Terdapat hubungan yang bermakna antara stimulasi ibu dengan perkembangan motorik kasar $(\mathrm{p}=0,004)$, motorik halus $(\mathrm{p}=0,025)$, personal sosial $(\mathrm{p}=0,001)$ dan bahasa $(\mathrm{p}=0,000)$.

\section{Pembahasaan}

Pemberian stimulasi motorik kasa diberikan berdasarkan tahapan usia, misalnya usia 0-1 tahun, usia 1-2 tahun, dan usia 1-2 tahun. Ibu mulai mengajak bayi meraba berbagai bentuk permukaan, seperti mainan binatang dan plastik serta memastikan bayi tidak memasukkan benda tersebut ke dalam mulut. Kemudian pada usia 1-2 tahun, ibu mengajari anak membuat untaian benda (misal : kancing besar) dengan tali yang cukup kuat dan usia 2-3 tahun, seperti mengajarkan anak untuk bermain kertas lipat, membuat lipatan segitiga dan persegi. Stimulasi personal sosial diberikan ibu sesuai tahapan usia perkembangan, misalnya pada usia 0-1 tahun seperti mengajak bayi tersenyum dengan suara-suara menyenangkan, usia 1-2 tahun contohnya mengajak anak membuat rumah-rumahan dan usia 2-3 tahun mengajak anak untuk membersihkan dirinya

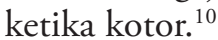

Sebagian besar responden $(54,5 \%)$ yang memberikan stimulasi personal sosial dalam kategori baik memiliki pendidikan terakhir SMA. Hal ini sesuai dengan penelitian Latifah ${ }^{11}$ yang melaporkan bahwa semakin baik tingkat pendidikan orang tua semakin baik juga kualitas stimulasi psikososial yang diberikan kepada anak. Hasil yang sama juga tampak pada stimulasi motorik kasar, 63\% responden memberikan stimulasi motorik kasar yang baik kepada anaknya. Marischa ${ }^{7}$ menyatakan bahwa pengetahuan orang tua mengenai stimulasi motorik kasar berhubungan dengan perkembangan motorik anak. Hal ini didukung oleh Soetjiningsih ${ }^{12}$ yang menyatakan bahwa responden dengan mayoritas berpendidikan sedang (SMP dan SMA) memiliki kemampuan cukup baik dalam menyerap informasi mengenai kesehatan anak, 
termasuk tentang stimulasi perkembangan. Selain itu, ibu dengan pendidikan sedang atau tinggi akan lebih mudah mencari dan menyerap informasi tentang perkembangan. Akan tetapi, hasil ini berbeda dengan penelitian Ariyana ${ }^{13}$ yang melaporkan bahwa sebagian besar ibu berpengetahuan baik memiliki tingkat pendidikan tinggi. Oleh karena itu, pengetahuan ibu sangat dipengaruhi oleh tingkat pendidikan.

Sementara itu, berdasarkan kategori usia, pemberian stimulasi personal sosial dan motorik kasar dalam kategori baik diberikan oleh ibu kategori usia 26-35 tahun. Usia 20-35 tahun merupakan usia yang produktif bagi seseorang untuk dapat memotivasi diri dalam memperoleh pengetahuan. ${ }^{14}$ Sebagian besar ibu memiliki pekerjaan sebagai ibu rumah tangga. Pemberian stimulasi motorik kasar kategori baik terbanyak diberikan oleh ibu dengan pekerjaan sebagai ibu rumah tangga, yaitu hampir dua per tiga responden dengan pekerjaan ibu rumah tangga $(61,7 \%)$. Hal ini sesuai dengan penelitian Kholifah ${ }^{15}$ yang melaporkan bahwa ibu rumah tangga atau ibu yang tidak bekerja akan memiliki waktu untuk berinteraksi atau menstimulasi anak lebih lama. Selain itu, pada ibu pekerja, mayoritas ibu akan kelelahan setelah pulang bekerja sehingga waktu untuk interaksi dengan anak berkurang. ${ }^{14}$ Ibu pekerja akan jarang memberikan stimulasi dibandingkan ibu yang tidak bekerja. ${ }^{16}$

Kami mendapatkan bahwa anak dengan kategori perkembangan normal lebih banyak dibandingkan dengan anak dalam kategori suspek pada seluruh aspek perkembangan. Hal ini sesuai dengan penelitian oleh Sumiyati ${ }^{17}$ yang melaporkan bahwa semua anak usia 4-5 tahun mempunyai kemampuan perkembangan motorik kasar dan motorik halus sesuai usia perkembangan. Anggraini ${ }^{18}$ melaporkan perkembangan sosial anak usia prasekolah sebagian besar adalah normal.

Penelitian Marischa ${ }^{7}$ di Lampung Tengah melaporkan bahwa terdapat seperempat $(25,2 \%)$ balita mengalami suspek perkembangan motorik kasar. Penelitian tersebut menemukan kemampuan motorik kasar paling banyak yang tidak dapat dilakukan anak usia 0-1 tahun adalah adalah mengangkat kepalanya. Untuk anak berusia $>1$ tahun - 2 tahun didapatkan 5 anak mengalami keterlambatan perkembangan, terbanyak adalah tidak bisa berdiri sendiri. Sementara anak berusia $>2$ tahun - 3 tahun terdapat 10 anak mengalami keterlambatan perkembangan motorik kasar, terbanyak adalah tidak bisa melompat. ${ }^{7}$
Berdasarkan analisis data didapatkan hubungan antara stimulasi yang diberikan dengan perkembangan anak, baik perkembangan motoik kasar, motorik halus, personal sosial, maupun bahasa. Penelitian Yanti $\mathrm{dkk}^{19}$ melaporkan hubungan antara stimulasi terhadap perkembangan motorik halus anak usia prasekolah (dengan bermain puzzle). Penelitian tersebut melaporkan bahwa semakin baik stimulasi, maka akan semakin normal perkembangan motorik halus seorang anak. Dua faktor utama yang berpengaruh terhadap tumbuh kembang anak adalah faktor keturunan (bawaan) dan lingkungan. Faktor keturunan merupakan modal utama dalam mencapai hasil akhir proses tumbuh kembang anak. Faktor bawaan meliputi jenis kelamin, suku, atau bangsa. Potensi bawaan yang bermutu hendaknya dapat berinteraksi dengan lingkungan secara positif sehingga diperoleh hasil akhir yang optimal. Teori yang menjelaskan secara detail tentang sistematika motorik anak adalah dynamic system theory yang dikembangkan Thelen dan Whiteneyerr. Teori tersebut mengatakan bahwa untuk membangun kemampuan motorik, anak harus mempersepsikan sesuatu di lingkungannya yang memotivasi mereka untuk melakukan sesuatu dan menggunakan persepsi mereka tersebut untuk bergerak. $^{20,21}$

Seluruh anak yang mendapat stimulasi personal sosial dalam kategori baik memiliki perkembangan personal sosial yang sesuai atau normal. Terdapat hubungan antara stimulasi personal sosial ibu dengan perkembangan personal sosial anak. Hal ini sejalan dengan penelitian Anggraini ${ }^{18}$ yang melaporkan hubungan yang bermakna antara stimulasi psikososial dengan perkembangan sosial anak usia prasekolah. Penelitian lain juga melaporkan bahwa terdapat hubungan yang bermakna mengenai pengaruh stimulasi psikososial terhadap perkembangan anak. ${ }^{11}$

Perkembangan anak dipengaruhi oleh faktor internal dan eksternal. Stimulasi termasuk faktor eksternal yang berperan penting dalam perkembangan anak. Stimulasi yaitu ketersediaan sarana untuk tumbuh kembang anak maupun peran serta orangtua atau orang sekitarnya untuk membantu proses tumbuh kembang anak. ${ }^{21}$ Penelitian yang dilakukan di Surabaya melaporkan bahwa anak yang mendapatkan stimulasi dari orang tuanya memiliki perkembangan motorik kasar yang sesuai atau normal. ${ }^{15}$

Penelitian lain melaporkan bahwa anak membutuhkan orang lain dalam perkembangannya dan 
orang yang paling pertama bertanggung jawab adalah orang tua. Oleh karena itu, stimulasi dari orang tua, terutama ibu yang merupakan orang terdekat dengan anak, berperan penting demi menunjang perkembang anak agar menjadi lebih optimal. ${ }^{22}$ Penelitian di Lampung melaporkan bahwa pengetahuan orang tua mengenai stimulasi motorik kasar memiliki hubungan yang bermakna dengan perkembangan motorik anak. Hal ini dikarenakan perkembangan anak akan lebih optimal jika mendapatkan stimulasi yang cukup dan terarah serta tepat sesuai usianya, terutama bagi batita yang masih tergolong memiliki usia yang disebut golden period (usia 0-3 tahun). ${ }^{7,12}$

Stimulasi yang diberikan pada anak di masa golden period yang sesuai dengan aspek tumbuh kembang akan mengoptimalkan perkembangan anak. ${ }^{22}$ Stimulasi yang dilakukan oleh orang tua memiliki pengaruh yang baik terhadap perkembangan anak usia kurang dari tiga tahun..$^{23}$ Terdapat hubungan antara pendidikan orang tua dan perkembangan motorik kasar anak usia 3-4 tahun. Orang tua dengan pendidikan minimal sedang (SMP dan SMA) akan lebih mudah menyerap informasi tentang pemberian stimulasi pada anaknya dibandingkan dengan ibu yang berpendidikan rendah (SD). ${ }^{24}$ Penelitian lainnya melaporkan terdapat hubungan yang bermakna antara tingkat pendidikan ibu terhadap perkembangan motorik kasar dan motorik halus pada balita. ${ }^{25}$

Hasil analisis bivariat juga menunjukkan terdapat hubungan antara stimulasi orang tua terhadap perkembangan bahasa anak. Sesuai dengan penelitian di Semarang yang melaporkan bahwa terdapat hubungan antara stimulasi perkembangan bahasa dengan tingkat kemampuan bahasa pada anak umur 1-3 tahun. Sementara itu, data lain menyebutk an terdapat hubungan antara stimulasi atau pola komunikasi orang tua terhadap perkembangan bahasa anak. ${ }^{26}$

Penelitian ini merupakan penelitian yang baru pertama kali dilakukan, yaitu dengan menilai hubungan antara stimulasi ibu terhadap perkembangan anak, baik perkembangan bahasa, motorik kasar, motorik halus dan personal social dengan menggunakan pemeriksaan Denver II yang dinilai langsung pada setiap responden. Sementara itu, penelitian ini hanya dilakukan oleh seorang dokter spesialis anak dan dibantu oleh asisten penelitian sehingga bisa terdapat bias intrapersonal karena kelelahan.

\section{Kesimpulan}

Sebagian besar orang tua khususnya ibu sudah memberikan stimulasi yang baik terhadap perkembangan anak. Stimulasi yang diberikan berhubungan dengan perkembangan anak baik perkembangan bahasa, motorik kasar, motorik halus, dan personal sosial.

\section{Ucapan terima kasih}

Ucapan terimakasih kami ucapkan kepada seluruh responden yang sudah turut dalam melakukan penelitian ini, para guru di Departemen anak FK Unila/RS Abdul Muluk, serta tim dalam pelaksanaan penelitian ini.

\section{Daftar pustaka}

1. Martani W. Metode stimulasi dan perkembangan emosi anak usia dini. J Psikologi 2012;39:112-20.

2. Depkes RI. Pedoman nasional tumbuh kembang anak. Jakarta: Gramedia; 2010.

3. Kolb B, Bryan DF. Handbook of clinical child neuropsychology. USA: Springer Science Business Media; 2009.

4. Yuliastanti T. Pola asuh dan perkembangan personal sosial anak toddler. J Komunikasi Kesehatan 2013;4:1-5.

5. Baker-Henningham H, Boo FL. Early childhood stimulation interventions in developing countries: a comprehensive literature review. IZA discussion papper series No. 5282. Bonn: IZA;2010.h.1-73.

6. Depkes RI. Pedoman pelaksanaan stimulasi, deteksi dan intervensi dini tumbuh kembang anak di tingkat pelayanan kesehatan dasar. Jakarta: Departemen Kesehatan Republik Indonesia; 2013.

7. Marischa S. Hubungan pengetahuan orang tua tentang stimulasi dengan perkembangan motorik kasar anak usia 0-5 tahun di Desa Bumi Aji Kecamatan Anak Tuha Kabupaten Lampung Tengah [skripsi]. Bandar Lampung: Fakultas Kedokteran Universitas Lampung, 2015.

8. Hartanto F, Hendriani S, Saldi F. Pengaruh perkembangan bahasa terhadap perkembangan kognitif anak usia 1-3 tahun. Sari Pediatri 2011;12:386-90.

9. Puskesmas Kedaton. Data perkembangan balita Puskesmas Kedaton. Bandar Lampung: Puskesmas Kedaton; 2011.

10. Depkes RI. Pedoman nasional tumbuh kembang anak. Jakarta: Gramedia; 2010.

11. Latifah E, Dwi H, Melly L. Pengaruh pemberian ASI dan stimulasi psikososial terhadap perkembangan sosial-ekonomi anak balita pada keluarga ibu bekerja dan tidak bekerja. J Ilmu Keluarga dan Konseling 2010;3:35-45. 
12. Soetjiningsih. Tumbuh kembang anak. Jakarta: EGC; 2012.

13. Ariyana D, Rini NS. Hubungan pengetahuan ibu tentang perkembangan anak dengan perkembangan motorik kasar dan halus anak usia 4-5 tahun di TK Bustanul Atfal 7 Semarang. J Keperawatan 2009;2:11-20.

14. Utina J, Palamani S, Tamunu E. Hubungan antara status bekerja ibu dengan pencapaian tumbuh kembang anak usia batita di Kelurahan Maasing kecamatan Tuminting Kota Manado. Juiperdo 2012;1:18-22.

15. Kholifah SN, Fadillah N, As'ari, Hidayat T. Perkembangan motorik kasar bayi melalui stimulasi ibu di kelurahan kemayoran Surabaya. J Sumber Daya Manusia Kesehatan 2014;1:106-22.

16. Azizah NN. Gambaran stimulasi perkembangan oleh ibu terhadap anak usia Prasekolah di TKIT Cahaya Ananda Depok [skripsi]. Depok: Universitas Indonesia, 2012.

17. Sumiyati, Yuliani DR. Hubungan stimulasi dengan perkembangan anak usia 4-5 tahun di Desa Karangtengah Kecamatan Baturraden Kabupaten Banyumas. J LINK 2016;12:34-8.

18. Anggraini S. Hubungan stimulasi psikososial dengan perkembangan sosial anak usia pra-sekolah di taman kanakkanak Kelurahan Sidomulyo Kecamatan Godean Kabupaten Sleman [skripsi]. Yogyakarta. Sekolah Tinggi Ilmu Kesehatan Jendral Ahmad Yani, 2013.
19. Yanti E, Fridalni N, Neta MD. Hubungan stimulasi terhadap perkembangan motorik halus anak prasekolah usia (3-5 tahun) di PAUD Al Mubaraqah Ampang Kecamatan Kuranji Tahun 2011. J STIKES Mercu Bakti Jaya 2011;1:1-10.

20. Chamidah AN. Deteksi dini gangguan pertumbuhan dan perkembangan anak. J Pendidikan Khusus 2009;5:83-93.

21. McGregor G. Yin BC, Cueto S, Glewwe P, Richter L, Strupp B. Developmental potential in the 5 years for children in developing countries. UK: Lancet 2007;369:60-70.

22. Susanto A. Perkembangan anak usia dini. Edisi 1. Jakarta: Prenada Media Grup; 2011.

23. Innike, Asri P. Pengaruh pelatihan stimulasi keluarga oleh ibu dalam bentuk tulisan dengan gambar terhadap perkembangan anak usia kurang dari 3 tahun. Sari Pediatri 2016;16:284.

24. Muchid A, Samiasih A, Mariyam. Hubungan pengetahuan ibu dengan perkembangan motorik kasar anak usia 3-4 tahun di Posyandu Budi Lestari Desa Tlogorejo Guntur Demak. Fikkes 2013;6:36-43.

25. Rifai A. Hubungan tingkat pendidikan ibu terhadap perkembangan motorik kasar dan motorik halus pada balita usia 9-48 bulan di Posyandu Puskesmas Nagaswidak [skripsi]. Palembang: Fakultas Kedokteran Universitas Muhammadiyah Palembang, 2019.

26. Hidayati RN dan Umu M. Hubungan pola komunikasi orang tua dengan perkembangan bahasa anak prasekolah (usia 2-5 tahun). J Penelitian Kesehatan 2013;8:1-7. 